\title{
ALGUNAS CUESTIONES SOBRE LAS REGLAS TÉCNICAS
}

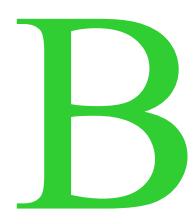

asta una ojeada a las obras de algunos de los autores que se han ocupado del fenómeno normativo para sentirse abrumado por la variedad y profusión de los tipos de normas que éstos suelen mencionar. Normas primarias, normas secundarias, reglas constitutivas, reglas regulativas, reglas que imponen deberes, reglas que confieren poderes, reglas permisivas, normas cualificatorias, reglas técnicas, prescripciones, reglas anankástico-constitutivas, reglas nómico-constitutivas, etc., son algunas de las entidades que aspiran a integrar el universo normativo. A veces se habla de distintos tipos de normas; otras, de sentidos diferentes del término. De algunos de estos tipos o sentidos se dice que son reductibles entre sí; de otros se dice lo contrario. Unos se consideran normas en un sentido central; otros, a veces, sólo en un sentido «periférico»... G. H. von Wright -uno de los autores más interesados por la filosofía de las normas- ha contribuido a esta proliferación de clases de normas distinguiendo tres tipos «principales» y tres tipos «menores»: por un lado, las reglas definitorias, las reglas técnicas o directrices y las prescripciones; por otro, las reglas ideales, los principios morales y las costumbres ${ }^{1}$.

Sostener la existencia de alguno o algunos de estos tipos de normas (o negar su especificidad) hace necesario entrar en una serie de discusiones a las que, en última instancia, subyace un mismo problema: un problema que quizá podríamos llamar el de «las fronteras del fenómeno normativo». Ha sido usual distinguir entre lenguaje descriptivo y lenguaje prescriptivo y confinar el fenómeno normativo dentro del lenguaje prescriptivo. Esta tesis tiene importantes consecuencias

${ }^{1}$ G. H. von Wright, Norma y acción, cap. I («De las normas en general»), Ed. Tecnos, 1979, trad. Pedro García Ferrero, págs. 21-37. 
para la filosofía práctica en general (como la ley de Hume) y para la filosofía del Derecho en particular (como el prescriptivismo jurídico). Pero muchos filósofos se han opuesto a esta reducción de todos los tipos de normas al lenguaje prescriptivo, señalando que para muchos enunciados que consideraríamos normativos es tan inadecuada la calificación de prescripciones como la de descripciones. Las reglas constitutivas serían un ejemplo. Otro podría estar constituido por las reglas técnicas.

Las reglas o normas técnicas han generado perplejidades (¿pueden considerarse verdaderas o falsas?), confusiones (¿qué diferencia existe entre las reglas técnicas y la descripción de una relación entre medios y fines?) y propuestas basadas en malentendidos (por ejemplo, cuando se afirma que todas las normas de los ordenamientos jurídicos son reglas técnicas) que sugieren que en ellas el problema de las «fronteras del fenómeno normativo» se suscita de una manera especialmente intensa. Con el fin de tratar de hacer alguna aportación a su estudio, voy a exponer más o menos sistemáticamente algunas observaciones que, de una manera dispersa, aquí y allá, ha señalado von Wright acerca de las reglas o normas técnicas (1) y, seguidamente, propondré una reconstrucción de estas observaciones a la luz de ciertas nociones de la teoría de los actos de habla de John Searle (2).

\section{Las reglas técnicas o directrices en la obra de von Wright}

\subsection{Las reglas técnicas y las proposiciones anankásticas.}

Las reglas técnicas o directrices, señala von Wright en Norma y acción, «guardan relación con los medios a emplear para alcanzar un determinado fin $\rangle^{2}$. No nos obligan a asumir determinados fines, pero -de alguna manera- nos «imponen» los medios para conseguir tales fines. Por ello, uno de los elementos necesarios en las normas técnicas es el deseo o la intención del agente de alcanzar un determinado fin: La formulación típica de estas normas adopta la forma de una

${ }^{2}$ Von Wright, Norma y acción, pág. 29. Von Wright parece asumir que estos medios han de ser condición necesaria del fin que se desea pero, como veremos más adelante, quizá también puede hablarse de reglas técnicas cuando el medio sea una condición suficiente del fin o simplemente una condición que contribuye a su realización. Otra cuestión que no queda clara en la obra de von Wright es si la relación entre medios y fines ha de ser causal o puede ser también de otro tipo (por ejemplo, lógica). De momento, entenderé que la relación es de necesariedad y de carácter causal, pero volveremos sobre esto al final del trabajo. 
oración condicional en cuyo antecedente se menciona la cosa que se desea y en cuyo consecuente se menciona «algo que tiene que (hay que, debe) o no tiene que hacerse» ${ }^{3}$. Las instrucciones para el uso serían ejemplos de directrices; asimismo, la oración «Si quieres hacer la cabaña habitable, tienes que calentarla», expresa, según von Wright, una norma técnica.

Las normas técnicas no deben confundirse con las normas hipotéticas, que tienen una formulación típica semejante. Estas son prescripciones «relativas a lo que debe, o puede, o tiene que no hacerse cuando surge determinada contingencia» ${ }^{4}$. Von Wright señala que «una diferencia entre normas hipotéticas y técnicas es que la respuesta a la pregunta ¿qué está sujeto a una condición? Es diferente para los dos tipos de norma. En el caso de la norma hipotética es el contenido de la norma lo que está sujeto a condición. En el caso de una norma técnica, es la existencia de la norma lo que está sujeto a condición. La oración 'si-entonces' dice: En el caso de que desees eso como fin (y no lo otro), entonces debes (puedes, tienes que no) hacer esto y esto» ${ }^{5}$. Las normas técnicas también deben distinguirse -pero la tarea es más difícil- de las proposiciones anankásticas.

Una proposición anankástica es un enunciado que afirma que una determinada cosa es una condición (necesaria) para un resultado, un enunciado que expresa una relación entre medios y fines. Las proposiciones anankásticas, a diferencia de las directrices, son descriptivas y, por tanto, verdaderas o falsas (es algo que veremos enseguida). Un ejemplo de proposición anankástica sería: «Para hacer la cabaña habitable, debe calentarse» (o «la cabaña no será habitable a menos que se la caliente» $)^{6}$. Entre reglas técnicas y proposiciones anankásticas existe una conexión lógica: «Cuando se da la directriz 'Si quieres hacer la cabaña habitable, tienes que instalar calefacción' se presupone (lógicamente) que si la cabaña no es acondicionada con calefacción no llegará a ser habitable». De manera que las normas técnicas se fundan siempre en proposiciones anankásticas.

La distinción entre normas técnicas y proposiciones anankásticas es, sin embargo, una distinción poco clara. Como señala Ricardo Guibourg, «afirma von Wright que las primeras presuponen las segundas, pero la diferencia entre ambas parece residir en la mayor o

${ }^{3}$ Von Wright, Norma y acción, pág. 29.

${ }^{4}$ Von Wright, Norma y acción, pág. 29.

${ }^{5}$ Von Wright, Norma y acción, pág. 179. «Si esto es así -añade von Wright- la propia norma técnica es categórica y no hipotética. La existencia de la norma, sin embargo, es hipotética».

${ }^{6}$ Von Wright, Norma y acción, pág. 29.

7 Von Wright, Norma y acción, pág. 29. 
menor personalización del enunciado y en el uso del modo imperativo. Acaso la distinción sería más clara si supusiéramos la proposición anankástica como «instalar calefacción es el único modo de hacer habitable la cabaña» (descripción de una necesidad técnica) y la directriz como «debo instalar calefacción» (apreciación normativa personalizada en relación con alguien que da por supuesto $s u$ deseo de llegar a cierto fin y asume por lo tanto la necesidad de adoptar el medio conducente a él)»» ${ }^{8}$

Una manera de concretar más estas distinciones y de precisar la relación de las normas técnicas con el razonamiento que guía la acción puede ser ponerlas en relación con la inferencia práctica, como hace von Wright en The Varieties of Goodness.

\subsection{Necesidades prácticas y normas técnicas}

En The Varieties of Goodness ${ }^{9}$ von Wright distingue tres aspectos de las normas: (1) normas como mandatos, (2) normas como reglas y (3) normas como necesidades prácticas. Estos tres aspectos de las normas tienen tres formulaciones típicas distintas: las oraciones imperativas, las oraciones con verbos deónticos y las oraciones con verbos anankásticos («tienes que») ${ }^{10}$. De estos tres aspectos de la norma, la necesidad práctica es el que más nos interesa en relación con las normas técnicas.

Una necesidad práctica surge de la combinación del deseo de un determinado fin con el conocimiento de los medios necesarios para alcanzar ese fin. El esquema de este silogismo -o de una de las modalidades del mismo- es como sigue:

a) Tu quieres $q$.

b) A menos que hagas $p$, no conseguirás $q$.

c) Por tanto, tienes que hacer $p$.

La primera premisa expresa un deseo; la segunda premisa expresa una necesidad causal; por último, la conclusión expresa lo que von Wright propone llamar una necesidad práctica $^{11}$. Desde

${ }^{8}$ Ricardo Guibourg, «La teoría de las normas en Georg Henrik von Wright», Anuario de Filosofía Jurídica,y Social, núm. 5, 1985, pág. 97.

${ }^{9}$ Von Wright, The Varieties of Goodness, Routledge \& Kegan Paul, Londres, 1963, págs. 157 y ss.

${ }^{10}$ No obstante, la correspondencia entre los aspectos de la norma y sus «contrapartidas» lingüísticas, como reconoce von Wright, no se mantiene rigurosamente en el lenguaje ordinario.

${ }^{11}$ Von Wright, The Varieties of Goodness, pág. 161. 
esta perspectiva, una norma técnica como «Si quieres $q$, tienes que hacer $p$ » es «una forma contraída del silogismo que, saltando la segunda premisa, procede directamente de la primera premisa a la conclusión» ${ }^{12}$. De manera que las reglas técnicas participan de los tres componentes de un silogismo práctico: un enunciado que expresa un deseo; un enunciado que expresa una necesidad natural, que es la proposición anankástica en la que se fundamenta la norma técnica; y, por último, una conclusión que expresa una necesidad práctica.

1.3. Normas técnicas y la ley de Hume. Relaciones entre normas técnicas y normas deónticas

Uno de los intentos de derivación del deber ser a partir del ser se debe a Max Black, quien toma, precisamente, a los juicios normativos técnicos y a la inferencia práctica como eje de la argumentación. El ejemplo de Max Black es el siguiente:

a) $A$ quiere dar jaque mate a $B$.

b) A menos que $A$ mueva la reina no podrá dar jaque mate a $B$.

c) $A$ debe mover la reina.

Tanto a) como b) son premisas descriptivas. La conclusión c) es, sin embargo, según este autor, una premisa descriptiva ${ }^{13}$. Que se use como ejemplo el juego del ajedrez puede provocar el error de suponer que se trata de una argumentación semejante a la de Searle ${ }^{14}$, pero lo relevante aquí no es que se trate de un contexto institucional (el juego, en este caso; la promesa, en el intento de Searle): si $A$ debe mover la reina no es porque ése sea un movimiento necesario para jugar al ajedrez -seguiría jugando aun cuando no lo hiciera-, sino porque es la única manera de dar jaque mate en esa situación.

En contra de Black, von Wright niega que nos encontremos ante un caso en el que se haya producido un paso del ser al deber ser. La conclusión, para von Wright, es un deber técnico, que pertenece al

${ }^{12}$ Von Wright, The Varieties of Goodnees, pág. 162.

${ }^{13}$ Sobre el intento de Black de derivar enunciados prescriptivos de enunciados descriptivos puede verse G. H. von Wright, «Is and Ought», en Man, Law and Modern Forms of Life, E. Bulygin et al. (eds.), pág. 265 y ss.; y José Hierro, Problemas del análisis del lenguaje moral, Ed. Tecnos, Madrid, 1970, pág. 144 y ss.

${ }^{14}$ Para John Searle puede pasarse del «ser» al «deber ser» dentro de ciertos sistemas institucionales. Véase Actos de habla, Ed. Cátedra, 1980, Cap. VI: «La falacia de la falacia naturalista». 
mundo del $\operatorname{ser}^{15}$. Pero lo interesante es que estos deberes técnicos pueden aparecer enlazados a deberes genuinamente normativos, lo que puede hacer difícil distinguirlos. Por un lado, un deber técnico -señala von Wright- puede respaldar una norma jurídica o una orden, puede ser parte del razonamiento que lleva a promulgar una ley u ordenar algo. Por otro lado -continúa-, dado un deber deóntico, puede ser que consideremos que, a menos que hagamos $x$ o $y$, no podremos cumplir con ese deber; entonces surge un deber técnico, una necesidad práctica, de la existencia de un deber deóntico ${ }^{16}$. Si consideramos la posibilidad de que los deberes deónticos den lugar a deberes técnicos, entonces es fácil confundir unos y otros.

\subsection{Reglas técnicas y verdad}

En Un ensayo de lógica deóntica y la teoría general de la acción ${ }^{17}$ von Wright sugiere que la cuestión de la verdad o falsedad de las normas puede ponerse en relación con la cuestión acerca de cómo se relacionan las normas de un sistema dado con algún conjunto de fines o valores. «Las normas que en sentido estricto pueden ser derivadas de un conjunto dado de fines -afirma von Wright- pueden considerarse verdaderas o falsas con relación a esos fines (y a las restricciones a la posibilidad natural) $){ }^{18}$.

Para comprender este específico sentido de «verdad» que depende de su relación con fines conviene introducir, por un lado, la distinción entre posibilidad o capacidad natural y posibilidad o capacidad deóntica y, por otro, el concepto de «árbol de la vida».

1.4.1. Pueden distinguirse (entre otros) dos tipos de posibilidad de actuar o capacidad: la posibilidad natural y la posibilidad deóntica. La capacidad natural es «capacidad sujeta sólo a las restricciones impuestas por las leyes de la naturaleza, incluyendo las limitaciones a la capacidad innata del hombre para crecer y aprender ${ }^{19}$. Por el contrario, cuando decimos en un sentido deóntico o normativo que un agente puede hacer cierta cosa, «queremos decir que al hacer esta cosa no violará un conjunto de reglas (normas) o condiciones tales

${ }^{15}$ Von Wright, «Is and Ought», pág. 277.

${ }^{16}$ Von Wright, «Is and Ought». págs. 276 y 277.

${ }^{17}$ Von Wright, Un ensayo de lógica deóntica y la teoría general de la acción, UNAM, 1976, trad. Ernesto Garzón Valdés.

${ }^{18}$ Von Wright, Un ensayo de lógica deóntica y la teoría general de la acción, pág. 85.

${ }^{19}$ Von Wright, Un ensayo de lógica deóntica y la teoría general de la acción, pág. 69. 
como, por ejemplo, las reglas de un cierto orden jurídico o de un código moral» ${ }^{20}$. Partiendo de estos dos conceptos, podemos distinguir entre un «árbol de la vida natural» y un «árbol de la vida deóntico». El primero "es una representación de cómo una persona puede vivir (arreglar su vida) dentro de los límites de sus capacidades y del orden causal»» ${ }^{21}$; el segundo «refleja un orden normativo o 'ley' que regula la vida de un individuo (a lo largo de un cierto lapso, contando desde el presente) (...). En el árbol podemos ver o 'leer' exactamente lo que este individuo está obligado o tiene permitido hacer en cada etapa y en cada una de las vidas posibles que él puede vivir 'legítimamente'»" ${ }^{22}$. Así, «la forma de un árbol de la vida naturalista puede decirse que refleja una ley u orden natural», mientras que «la forma de un árbol de la vida deóntico refleja una ley u orden normativo» ${ }^{23}$.

Supongamos -sugiere von Wright- un árbol de la vida sin limitaciones naturales ni deónticas (un «árbol de la vida lógico»). Tanto el árbol de la vida naturalista como el árbol de la vida deóntico surgen de este árbol sin restricciones a través de un proceso de «poda». El resultado de esta poda son las leyes de la naturaleza y las leyes de los sistemas normativos. ¿Cuáles son los criterios («principios») para reducir el árbol de la vida lógico a un determinado árbol de la vida deóntico?

En opinión de von Wright, «un caso extremo es cuando el principio o los principios hacen posible una rigurosa derivación lógica de lo que debería ser obligatorio, permitido y prohibido en el curso de cualquier vida posible del individuo o individuos en cuestión» ${ }^{24}$. Supongamos, por ejemplo, una ética utilitarista. Si aceptamos que podemos dar un contenido preciso a la noción de bondad, podemos utilizar el principio moral supremo utilitarista para extraer del árbol lógico la forma exacta del árbol deóntico de la vida. Este sería un ejemplo de cómo las normas se relacionan con ciertas bases axiológicas ${ }^{25}$.

1.4.2. Detrás de muchas normas podemos encontrar (más o menos explícitamente) fines o valores. Detrás de las normas jurídicas, por ejemplo, encontramos fines que «consisten en cosas tales como el mantenimiento del orden y la seguridad, una justa distribución de los bienes materiales y culturales, etc.» Ahora bien, «estos

${ }^{20}$ Von Wright, Un ensayo de lógica deóntica y la teoría general de la acción, pág. 69.

${ }^{21}$ Von Wright, Un ensayo..., pág. 67.

${ }^{22}$ Von Wright, Un ensayo..., págs. 79 y 80.

${ }^{23}$ Von Wright, Un ensayo..., pág. 83.

${ }^{24}$ Von Wright, Un ensayo..., pág. 84.

${ }^{25}$ Von Wright, Un ensayo..., pág. 84. 
fines axiológicos situados detrás del orden jurídico muy pocas veces, quizá nunca, están claramente articulados. Por esta razón no es fácil pensar que las normas de un orden jurídico sean derivables, en un sentido lógico estricto, de los fines o valores a los que se supone (vagamente) que sirve este orden jurídico en su totalidad $»^{26}$.

De manera que podríamos trazar un continuo o una escala según la relación de las normas con los fines, esto es, según la intensidad con la que éstas fueran derivables de ciertos fines. En un extremo de este continuo estarían las normas puramente convencionales (como las reglas de los juegos), que no tendrían ninguna relación con la verdad. En el otro extremo estarían las reglas técnicas, que serían «verdaderas o falsas con relación a aquellos fines [de los que pueden derivarse] $\gg^{27}$.

\section{Una reconstrucción: reglas técnicas y actos de habla}

\subsection{El filósofo indiscreto. Ambigüedad y acto de habla indirectos}

Creo que muchas de las dificultades para esclarecer el concepto de regla técnica se deben a ciertas confusiones entre a) regla técnica, b) proposición anankástica y c) necesidad práctica (o deber técnico). En este apartado voy a tratar de ofrecer algunas pautas para trazar una distinción más nítida entre estos tres conceptos. Para ello, voy a considerar a las reglas técnicas como el resultado de un acto de habla básicamente directivo, con lo que hago depender su existencia del lenguaje. En el siguiente apartado sugeriré las características peculiares de los actos de habla cuyo resultado son reglas técnicas.

El punto de partida en este apartado serán las siguientes dos advertencias (de las cuales el segundo supuesto puede considerarse un caso extremo del primero): 1) Un mismo enunciado puede expresar, según el contexto, una proposición anankástica o una regla técnica y 2) un enunciado con la forma característica de las proposiciones anankásticas puede expresar en realidad una regla técnica y un enunciado con la forma característica de las reglas técnicas puede expresar en realidad una proposición anankástica.

Trataré de mostrar esto con ejemplos.

2. 1. 1. Un profesor de filosofía cena solo en un restaurante. Nuestro filósofo apenas presta atención a lo que está comiendo, tal es su grado de abstracción. La capacidad para «estar en las nubes» es una de las características más comunes de los filósofos. La otra,

${ }^{26}$ Von Wright, Un ensayo..., pág. 85.

${ }^{27}$ Von Wright, Un ensayo..., pág. 85. 
probablemente, es su curiosidad, que a veces (como en este ejemplo) raya la indiscreción: de vuelta de sus cavilaciones nuestro personaje oye al azar un fragmento de la conversación de una mesa cercana. Alguien llamado Pedro le dice a alguien llamado Alfredo: "Si se quiere que el núcleo de un átomo se desintegre se le tiene que bombardear con partículas $\beta »$.

Nuestro filósofo sólo ha podido escuchar esta frase y carece de conocimientos en esa materia, pero ello no le impide entregarse a algunas especulaciones:

a) «Si se quiere que el núcleo de un átomo se desintegre se le tiene que bombardear con partículas $\beta »$. Eso es lo que ha dicho Pedro. Es razonable poner estas palabras en boca de un físico; Alfredo -observa el filósofo-, por el contrario, tiene aires de empresario. Probablemente Alfredo haya estado tratando de desarrollar alguna invención que le resulte lucrativa, pero no ha logrado tener éxito. Quizá Alfredo ha invitado a cenar a Pedro para preguntarle qué debe hacer para tener éxito en el experimento, y la frase que ha llegado a oídos del filósofo es la respuesta de Pedro. Alfredo ha planteado una demanda, pero no una demanda de información descriptiva. A Alfredo no le interesa un determinado conocimiento teórico, le tiene sin cuidado. Alfredo quiere saber qué hacer, no qué pasa si tal cosa o tal otra sucede. Es un «interesado», no un «curioso»: Alfredo plantea una pregunta cuya respuesta satisfactoria es un enunciado con una «dirección de ajuste mundo a palabras» ${ }^{28}$.

${ }^{28}$ «Algunas ilocuciones tienen como parte de su objeto ilocucionario el llevar a las palabras (más estrictamente, su contenido proposicional) a encajar con el mundo, otras el llevar al mundo a encajar con las palabras. Las aserciones pertenecen a la primera categoría, las promesas y ruegos a la segunda». John Searle, «Una taxonomía de los actos ilocucionarios», Teorema, vol. VI/1, 1976, pág. 45.

El concepto de «dirección de ajuste» se entiende fácilmente con un ejemplo: Supongamos que un hombre va al supermercado con una lista de compras que le ha dado su mujer en la que están escritas las palabras «habas, mantequilla, bacon y pan». Supongamos que mientras él anda por allí con su carrito seleccionando esos elementos es seguido por un detective que escribe todo lo que él coge. Cuando salen de la tienda, comprador y detective tendrán listas idénticas, pero la función de ambas listas será completamente diferente. En el caso de la lista del comprador el propósito de la lista es, por así decirlo, llevar al mundo a encajar con las palabras (dirección de ajuste mundo a palabras). Si cuando el comprador vuelve a casa su mujer le advierte que ha comprado chuletas de cerdo en lugar de bacon, el error no puede corregirse cambiando la lista. En el caso del detective el propósito de la lista es, por el contrario, hacer que las palabras encajen con el mundo (dirección de ajuste palabras a mundo). Si el detective vuelve a casa y se da cuenta de que el comprador había comprado chuletas en lugar de bacon, puede corregir el error simplemente cambiando la lista.

El ejemplo es de G. E. M. Ascombe, Intención, Ed. Paidós, 1991, pág. 109.Citado también en Searle, «Una taxonomía de los acto ilocucionarios», págs. 45 y 46. 
Nuestro filósofo, estudioso de la filosofía de las normas, puede llegar entonces a la conclusión de que el enunciado de Pedro - «Si se quiere que el núcleo de un átomo se desintegre se le tiene que bombardear con partículas $\beta »-$ era una regla técnica. Se trata de indicarle a Alfredo qué es lo que tiene que hacer, puesto que desea tener éxito en su experimento. Se trata de responder a la pregunta «¿qué hacer?». Obviamente, con esto Pedro también está transmitiendo cierta información: nuestro filósofo, al oír la regla técnica, aprende que un núcleo atómico se desintegra cuando recibe un bombardeo de partículas $\beta$. Pero esto no es una peculiaridad de las reglas técnicas. Como recuerda Guibourg, sea cual sea la forma gramatical empleada, «las distintas funciones del lenguaje rara vez se nos presentan en forma pura. Una orden pretende obtener de nosotros una conducta, pero a la vez nos proporciona cierta información sobre las preferencias de quien la emite, y es fácil hallar también en ella la expresión de cierta actitud emotiva: el deseo del emisor por aquello que prescribe, o su rechazo por aquello que prohíbe $)^{29}$. En el caso de las reglas técnicas, una «función secundaria» de carácter descriptivo se muestra -por las razones que más adelante veremos- de manera especialmente fuerte (lo que hace difícil distinguir la regla técnica de la proposición anankástica y, consecuentemente, nos lleva a pensar que las reglas técnicas cierta relación con la verdad) ${ }^{30}$. Pero es posible imaginar contextos (como el de nuestro ejemplo) en el que la función directiva de estas reglas aparece «más pura».

b) Sin embargo, -continúa el filósofo de nuestro ejemplo-, es también muy posible que tanto Pedro como Alfredo sean compañeros de trabajo. Quizá se trata de una conversación entre dos físicos en la que se discute acerca de ciertas relaciones causales. Quizá Pedro acaba de hacer un importante descubrimiento y está describiendo a Alfredo una regularidad que ha observado: si y sólo si un núcleo atómico es bombardeado con partículas $\beta$, se desintegra. De manera que bombardear un núcleo atómico con partículas $\beta$ es necesario para desintegrarlo. Alfredo puede encontrar esto sumamente interesante: ¿Interesante, para qué? Interesante... para nada. Interesante sin más. Alfredo es «curioso», no «interesado». Simplemente quiere saber, reducir su ignorancia. Quizá la conversación se ha iniciado porque Alfredo ha preguntado: «¿cuándo, en qué condiciones, se puede desintegrar un núcleo atómico?»; y Pedro le

\footnotetext{
${ }^{29}$ Ricardo Guibourg, Introducción al conocimiento jurídico, Ed. Astrea, Buenos Aires, 1984, pág. 100.

${ }^{30}$ Como veremos más adelante, algunos autores, por ejemplo John Searle, consideran que todos los enunciados tienen un contenido proposicional o descriptivo.
} 
ha contestado: «Si se quiere que el núcleo de un átomo se desintegre se le tiene que bombardear con partículas $\beta »$. Este enunciado expresa entonces una proposición anankástica. Pedro podría haber contestado: «Bombardear con partículas $\beta$ es la única manera de que un núcleo atómico se desintegre». Si lo hubiera hecho así, la finalidad meramente descriptiva de su contestación hubiera sido quizá más clara. Pero en ciertos contextos (como en el de nuestro ejemplo) la función primaria descriptiva del enunciado no da lugar a confusiones. Su «dirección de ajuste» es «palabras a mundo»: no se trata de que Alfredo haga algo, sino de que aprenda algo acerca del mundo.

2.1.2. Hasta aquí no he hecho nada más que repetir algunas cuestiones básicas acerca de las diferencias entre discurso teórico y discurso práctico, pero lo he hecho tratando de mostrar que en los enunciados en los que aparecen términos anankásticos se da una ambigüedad semejante a la ambigüedad de los enunciados en los que aparecen términos deónticos. Una misma oración con un verbo deóntico puede expresar tanto una prescripción como una proposición normativa. Una misma oración con un verbo anankástico puede expresar tanto una proposición anankástica como una regla técnica. Esta ambigüedad, sin embargo, no es del todo paralela a la ambigüedad de los enunciados deónticos. Por proposición normativa entendemos una descripción acerca de la existencia de la norma, pero la proposición anankástica no es una descripción acerca de la existencia de la regla técnica, sino acerca de un vínculo entre medios y fines que fundamenta -junto con un deseo- la existencia de la regla.

Esta ambigüedad puede dar lugar a muchas confusiones, e incluso puede llevarnos a no tener siempre presente la distinción entre reglas técnicas y proposiciones anankásticas. Pero mantener la distinción entre lenguaje descriptivo y lenguaje directivo, y mantenerla como una distinción entre términos mutuamente excluyentes ${ }^{31}$, exige trazarla con la mayor nitidez posible. Guibourg sugería que la diferencia entre reglas técnicas y proposiciones anankásticas parece residir «en la mayor o menor personalización del enunciado y en el uso del modo imperativo ${ }^{32}$. Esta afirmación debe entenderse en el sentido de que las proposiciones anankásticas y las reglas técnicas tienen respectivamente una forma típica o característica, pero no debe entenderse de manera que se

${ }^{31}$ Que descripciones y directivas sean categorías mutuamente excluyentes no significa que un mismo enunciado no pueda expresar una descripción y una directiva, sino que su significado descriptivo no tiene significado directivo, y viceversa.

${ }^{32}$ Ricardo Guibourg, «La teoría de las normas en G. H. von Wright», pág. 97. 
excluya la posibilidad de que un mismo enunciado sea ambiguo y pueda expresar tanto una proposición anankástica como una regla técnica.

Las diferencias que señala Guibourg entre una y otra formulación son la mayor o menor personalización de las oraciones y el uso del modo imperativo. Por lo que respecta al uso del imperativo, si asumimos la distinción entre verbos imperativos, verbos deónticos y verbos anankásticos, parece que es característico tanto de las proposiciones anankásticas como de las reglas técnicas el uso de verbos anankásticos, como señalaba von Wright en The Varieties of Goodness. Por tanto, el uso del imperativo no lo es, aunque puede utilizarse tanto el imperativo ( $\ll \mathrm{Si}$ quieres $\mathrm{p}$, haz $q »)$ como las modalidades verbales deónticas ( $\mathrm{Si}$ quieres $p$, debes hacer $q »)$ para formular reglas técnicas. Por otro lado, otra diferencia (muy vinculada a la anterior) que se puede observar en la formulación es el modo distinto de referirse al fin. En los enunciados (típicos) que expresan proposiciones anankásticas el fin se describe de una manera que podríamos considerar «neutral», en el sentido no comprometido de «la consecuencia de emplear un determinado medio». Quizá fuera más exacto hablar de causas y efectos, en lugar de medios y fines, por lo menos cuando la relación sea causal. Por el contrario, en la formulación que propongo considerar típica de las reglas técnicas el fin se valora como un fin deseado.

De manera que la formulación típica de las reglas técnicas tendría que reunir las siguientes características:

a) mayor personalización;

b) fin como algo deseado.

Por ejemplo:

«Si quieres hacer la cabaña habitable, tienes que calentarla».

La formulación típica de las proposiciones anankásticas reuniría, por el contrario, las siguientes características:

a) despersonalización (sin referencia a sujetos)

b) mención del fin de una manera neutra, sin que exprese que se trata de un fin deseado.

Por ejemplo:

«Para hacer la cabaña habitable, tiene que calentarse».

Pero -como ya he dicho- la diferencia esencial entre reglas técnicas 
y proposiciones anankásticas no hay que buscarla en sus formulaciones canónicas, sino en su diferente función. Considerar a las reglas técnicas como un tipo de normas implica considerarlas como pautas para guiar la acción, esto es, implica atribuirles una función directiva. La función de las normas técnicas no es describir, sino responder a la pregunta «¿qué hacer?».

2.1.3. Imaginemos que en las circunstancias a) de nuestro ejemplo (Pedro es un físico; Alfredo un empresario) la respuesta de Pedro a la pregunta «¿qué hago?» que le ha dirigido Alfredo es la siguiente: «Los núcleos atómicos se desintegran al bombardearlos con partículas $\beta »$ ¿ ¿Es ésta una respuesta satisfactoria a la pregunta de Alfredo? Alfredo pedía que se guiara su acción y Pedro le informa de una regularidad causal. La respuesta adecuada habría sido, sin embargo, algún enunciado con una función directiva, no descriptiva. ¿Es posible que Pedro no haya oído la pregunta? ¿Aparenta no haberla oído y quiere apartarse del tema? Si Alfredo es mínimamente inteligente, comprenderá que, a través de una descripción, se le está indicando lo que tiene que hacer. Pero entonces, ¿se trata realmente de una descripción (una proposición anankástica)? ¿O es más bien una regla técnica?

Supongamos ahora las circunstancias b) de nuestro ejemplo (Pedro y Alfredo son físicos). La intención de Pedro es describir un descubrimiento suyo: algo que ocurre en el mundo físico. Supongamos que con esta intención Pedro le dice a Alfredo (que no tiene ningún interés práctico, por lo menos directamente, en este conocimiento): «Si quieres desintegrar un núcleo atómico, tienes que bombardearlo con partículas $\beta$ ». ¿Qué más le da a Alfredo lo que tiene que hacer, si -distraído quizá en otras ocupaciones- nunca se ha planteado la desintegración de los núcleos atómicos? ¿Por qué le dice Pedro a Alfredo lo que tiene que hacer si quiere desintegrar núcleos atómicos, si él nunca ha manifestado esa intención? ¿Se ha vuelto loco Pedro? En realidad, Pedro no está tratando de dirigir la conducta de Alfredo. Está tratando de informarle de cierta regularidad de la naturaleza y ha optado -quizá para dar más énfasis a sus palabras, para llamar mejor la atención de Alfredopor la formulación típica de las reglas técnicas. Entonces, ¿se trata realmente de una regla técnica o de una proposición anankástica?

2.1.4. Una de las razones que pueden oscurecer la distinción entre reglas técnicas y proposiciones anankásticas reside en la posibilidad de actos de habla indirectos en los que la emisión de una oración que tiene un significado descriptivo (la descripción de una regularidad de la naturaleza, en nuestro caso) tiene, además, un significado primario directivo (la posibilidad contraria también se da). 
La distinción entre acto de habla ilocucionario ${ }^{33}$ directo e indirecto ha sido señalada por Searle $^{34}$ en los siguientes términos: En nuestra conducta verbal suele ocurrir que lo que decimos y lo que queremos decir coincide, esto es, la fuerza ilocucionaria que pretendemos darle a nuestras palabras es justamente la que tienen. En estos casos (los casos más simples de significado) hablamos de actos de habla directos. Pero puede ocurrir también que la fuerza ilocucionaria principal de lo que decimos no coincida con la aparente; en palabras de Searle: «(...) no todas las clases de significado son así de simples: en indirectas, insinuaciones, lenguaje irónico y lenguaje metafórico -para mencionar un puñado de ejemplos- el significado de la emisión del hablante y el significado de la oración se separan de diferentes maneras. Una clase importante de tales actos es aquella en la que el hablante emite una oración, quiere decir lo que dice, pero también quiere decir algo más. Por ejemplo, un hablante puede emitir la oración Necesito que lo hagas para pedir al oyente que haga algo. Incidentalmente la oración se intenta como un enunciado, pero también se intenta primariamente como una petición, una petición hecha al hacer un enunciado» ${ }^{35}$. Nos encontramos en estos casos ante actos de habla indirectos. «¿Tienes hora?», «Me estás pisando», «Todos nos sentiríamos un poco mejor si te callaras un poco» y «¿Podrías apartarte de mi esposa, por favor?», son ejemplos de actos de habla (directivos) indirectos.

De manera que no sólo es posible que un enunciado sea ambiguo y pueda expresar, según el contexto, una regla técnica o una proposición anankástica (como vimos en 2.1.1), sino que también puede ocurrir (como un caso especial del anterior supuesto) que un enunciado que tenga la forma canónica propia de una regla técnica cumpla en realidad la función de una proposición anankástica y viceversa (como hemos visto en 2.1.3).

${ }^{33}$ «Cuando alguien dice algo debemos distinguir: a) el acto de decirlo, esto es, el acto que consiste en emitir ciertos ruidos con cierta entonación o acentuación, ruidos que pertenecen a un vocabulario, que se emiten siguiendo cierta construcción y que, además, tienen asignado cierto «sentido» y «referencia». Austin denomina a esto el acto locucionario, o la dimensión locucionaria del acto linguístico; b) el acto que llevamos a cabo al decir algo: prometer, advertir, afirmar, felicitar, bautizar, saludar, insultar, definir, amenazar, etc. Austin llama a esto el acto ilocucionario, o la dimensión ilocucionaria del acto lingüístico; y c) el acto que llevamos a cabo porque decimos algo: intimidar, asombrar, convencer, ofender, intrigar, apenar, etc. Austin llama a esto el acto perlocucionario o la dimensión perlocucionaria del acto lingüístico». Genaro R. Carrió y Eduardo Rabossi, «La filosofía de John L. Austin». nota preliminar a J. L. Austin, Cómo hacer cosas con palabras, Ed. Paidos, 1988, pág. 32.

${ }^{34}$ Searle, «Actos de habla indirectos», Teorema, vol. VII/1, 1977, págs. 23-53.

${ }^{35}$ Searle, «Actos de habla indirectos», pág. 23. 
2.1.5. La diferencia entre reglas técnicas y proposiciones anankásticas nos ha obligado a recurrir a una concepción pragmática del significado. Esta concepción parte de la constatación de que «comunicar algo equivale a querer decir algo, junto con el reconocimiento de que eso era lo que se pretendía decir» ${ }^{36}$, de manera que «el significado de las proferencias y el reconocimiento de la intención del hablante, en una ocasión dada de su conducta verbal, se nos aparecen firmemente vinculados ${ }^{37}$. Al recurrir a las circunstancias del contexto descubríamos cuál era la intención del hablante y podíamos interpretar su acción como un intento de guiar la conducta del oyente o como un intento de informar de alguna regularidad de la naturaleza. Con todo ello estoy supeditando la existencia de las reglas técnicas al lenguaje y a la conducta verbal de las personas. Sin embargo, resulta tentador pensar que las reglas técnicas son entidades objetivas cuya existencia no depende del lenguaje. Al fin y al cabo, si para que un núcleo atómico se desintegre hay que bombardearlo necesariamente con partículas $\beta$ y si yo quiero desintegrar un núcleo atómico, entonces yo tengo el deber técnico de bombardearlo con partículas $\beta$, con independencia de que alguien me lo advierta o no. Mi deber técnico no depende de ningún acto de habla. Lo mismo ocurre si quiero hacer habitable una cabaña o vivir muchos años con buena salud. En tales casos tengo los deberes técnicos de calentar la cabaña o no fumar excesivamente, y esto es así con independencia de que a alguien se le ocurra decirlo o no. Frente a una concepción «voluntarista» de las reglas técnicas (esto es, una concepción que hace depender su existencia de la intención con que un agente las formula en un lenguaje) cabría oponer una visión «objetivista» de las mismas.«No sólo estoy diciendo que la proposición anankástica es verdadera con independencia del lenguaje -diría un partidario de la concepción «objetivista»-; estoy advirtiendo de que lo es también la regla técnica».

Me parece, sin embargo, que debe distinguirse también entre regla técnica y deber técnico. El deber técnico pertenece al mundo del ser; esto queda más claro si lo llamamos necesidad práctica. Un agente tiene la necesidad práctica de hacer $x$ si tiene el deseo de $y$ y $x$ es un medio necesario para $y$. De manera que la necesidad práctica aparece en la conclusión de un silogismo práctico y surge de la combinación de un deseo y una relación de medio a fin. Basta con que en un agente se produzca esta combinación para que nazca su necesidad

${ }^{36}$ Juan José Acero, Eduardo Bustos y Daniel Quesada, Introducción a la filosofía del lenguaje, Ed. Cátedra, 1982, pág. 168.

${ }^{37}$ Juan José Acero, Eduardo Bustos y Daniel Quesada, Introducción a la filosofía del lenguaje, pág. 169. 
práctica o deber técnico de hacer una determinada cosa (incluso aunque él no sea consciente). Por tanto, la necesidad práctica es independiente del lenguaje. Esto es cierto; pero también lo es que existen ciertos actos de habla que se utilizan para dirigir la conducta de los demás señalando su necesidad práctica. Mientras las normas deónticas «crean» un deber, las reglas técnicas sugieren una actuación indicando un deber técnico ${ }^{38}$. Yo puedo tener una necesidad práctica y actuar o no en consecuencia, pero no habrá una regla en este caso salvo que alguien trate de dirigir mi conducta señalándome cuál es el contenido de mi necesidad práctica.

Por tanto, lo que es independiente del lenguaje es la relación de medio a fin que existe entre ciertos eventos. Lo que es independiente del lenguaje es, también, el deber técnico que ciertas personas pueden tener en determinadas circunstancias (en las que es relevante su deseo de algún fin). Vínculo anankástico y necesidad práctica pertenecen al mundo del ser, son objetivos. La necesidad práctica está fundada en el vínculo anankástico (que, en el caso de relaciones causales, es también una necesidad natural). Ese mismo vínculo anankástico fundamenta también la regla técnica, en el sentido de que ésta sólo será eficaz si se ajusta a ese vínculo. ¿Es posible que una regla técnica se apoye en una proposición anankástica falsa? ¿Diríamos entonces que se trata de una regla técnica ineficaz o, simplemente, que no es una regla técnica? Discutiremos esto más adelante.

Von Wright también parece ser de la opinión de que la existencia de las reglas técnicas depende de su formulación en algún lenguaje:

«¿Pueden las reglas técnicas, es decir, las normas concernientes a los medios necesarios para fines dados, existir sin formularse en el lenguaje? Puede, por supuesto, darse 'objetivamente' el caso de que algún agente deba hacer una determinada cosa para alcanzar un determinado fin que persigue, pero que ni él ni nadie más sea consciente de la conexión necesaria. La existencia de la conexión no depende de su formulación en palabras. Pero el vínculo anankástico no es lo mismo que la norma técnica. Por tanto, del carácter de independencia del lenguaje de la primera no se puede concluir la naturaleza independiente del lenguaje de la última» ${ }^{39}$.

${ }^{38}$ No hay que confundir esta necesidad práctica con la relación de condición necesaria que existe entre el medio y el fin. La necesidad práctica de hacer una determinada acción se tiene por la combinación del deseo de un fin y una relación de necesariedad entre un medio (la acción) y ese fin.

${ }^{39}$ Von Wright, Norma y acción, pág. 110. 
Y de que la necesidad práctica, en cambio, no lo es:

«Hemos llegado así a encontrar dos respuestas principales a la cuestión de por qué una cierta cosa debe o puede o no tiene que ser hecha. Una es que existe una norma ordenando o permitiendo o prohibiendo la realización de esa cosa. La otra es decir que los fines y las conexiones necesarias hacen (o no) la realización u omisión de esa cosa una necesidad práctica» ${ }^{40}$.

\subsection{Una propuesta: los actos de habla «directivo-instructivos»}

Hasta ahora he tratado a las reglas técnicas como el resultado de un acto de habla directivo. Esto es apropiado en un sentido amplio de directiva, caracterizado por tener una «dirección de ajuste mundo a palabras». En este sentido amplio (que nos ha permitido distinguirlas de las proposiciones anankásticas), las reglas técnicas, sin ser prescripciones, pertenecen al lenguaje directivo, al igual que los ruegos, las órdenes, las peticiones, etc. Pero hay ciertas características que tienen los actos de habla cuyo resultado son reglas técnicas que no tienen, por el contrario, los actos de habla cuyo resultado son ruegos, órdenes, peticiones o normas. Si esto es así, quizá pudiera sostenerse que las reglas técnicas no son propiamente el resultado de un acto de habla directivo, sino de un acto de habla muy semejante, pero con alguna variante. Dependiendo de la importancia que le demos a esta variante diremos que las reglas técnicas surgen de un acto de habla directivo especial o de un acto que habla de un tipo distinto. Se trata de una cuestión nominal. Lo importante es observar la diferencia entre las directivas típicas y las reglas técnicas. Por mi parte, hablaré de reglas técnicas como resultado de un acto de habla «directivo-instructivo» y no entraré en la cuestión de si es un tipo especial de los actos de habla directivos o un tipo distinto.

John Searle ha estudiado la estructura de los actos ilocucionarios, señalando cuáles son las condiciones cuya satisfacción garantiza la plena ejecución de los distintos tipos de actos de habla $\mathrm{a}^{41}$. Lo que voy a sostener es que las condiciones para el pleno éxito de los actos de habla directivos son distintas de las condiciones de los actos de habla «directivo-instructivos».

Searle distingue los siguientes tipos de condiciones:

\footnotetext{
${ }^{40}$ Von Wright, «The Foundation of Norms and Normative Statements», en Practical Reason, Basil Blackwell, 1983, pág. 74.

${ }^{41}$ John Searle, Actos de habla, Ed. Cátedra, 1980, trad. Luis M. Valdés Villanueva.
} 
a) Condiciones preparatorias: «tienen que ver tanto con el derecho que le asiste al ejecutante del acto para llevarlo a cabo, con la autoridad de que ha de estar investido para ello, como con las condiciones que deben darse en la ocasión concreta del habla para que su realización sea posible» ${ }^{42}$. La violación de uno o más de estos requisitos conlleva la no ejecución del respectivo acto de habla.

b) Condiciones de sinceridad: son las condiciones que afectan a las creencias o sentimientos apropiados que el hablante debe tener en su ejecución. Su violación no implica sin más la no ejecución del acto de habla, pero sí un «abuso» verbal.

c) Condición de contenido proposicional: es el contenido descriptivo mínimo que tiene todo acto de habla (por ejemplo, en el caso de las promesas, se describe una acción futura del hablante, etcétera).

d) Condiciones esenciales: tienen que ver con el tipo de compromisos que el hablante contrae por el hecho de haber dicho tales y cuales palabras.

Para comparar las condiciones de los tres tipos de acto de habla -descriptivos, directivos y directivos -instructivos- voy a utilizar un esquema de Searle ${ }^{43}$, al que añado una columna con las condiciones que me parece que deben reunir los actos de habla directivo-instructivos. Este esquema nos permite también ver las diferencias entre las proposiciones anankásticas (que reúnen las características de los descriptivos ${ }^{44}$ ) y las reglas técnicas. En él $H$ significa hablante, $O$ significa oyente, $A$ significa acción y $F$ fin.

\footnotetext{
${ }^{42}$ Juan José Acero, Eduardo Bustos, Daniel Quesada, Introducción a la filosofia del lenguaje, pág. 214.

${ }^{43}$ John Searle, Actos de habla, pág. 74.

${ }^{44}$ Para ver las características del acto de habla descriptivo cuyo resultado es una proposición anankástica basta con sustituir $p$ en el cuadro por cualquier vínculo anankástico.
} 


\section{Descriptivos Directivos Directivos-instructivos}

Condición preparatoria

Condición de sinceridad

Condición de contenido proposicional

Condición esencial
(1) $H$ tiene evidencia $O$ es capaz de realizar $A$ (1) $H$ tiene razones para (razones para la verdad) de $p$.

(2) No es obvio ni para $H$ ni para $O$ que $O$ sabe que $p$.

$H$ cree que $p$.

$H$ desea que $O$ haga $A$.

la verdad de $\ll A$ es condición necesaria de $F \gg$.

(2) No es obvio ni para $H$ ni para $O$ que $O$ sabe que $A$ es condición necesaria de $F$.

(3) $O$ desea $F$.

(4) $O$ es capaz de realizar $A$.

(1) $H$ cree que $A$ es condición necesaria de $F$. (2) $H$ desea que $O$ haga $A$ porque $O$ desea $F$.

cualquier proposición $p H$ predica un acto futuro(1) $H$ predica un acto de $O$. futuro de $O$.

(2) $H$ predica una necesidad práctica de $O$.

cuenta primariamentecuenta primariamentecuenta primariamente como la asunción de quecomo un intento de $H$ decomo un intento de $H$ de $p$ representa un estadollevar a $O$ a hacer $A$. llevar a $O$ a hacer $A$ de cosas real. porque $O$ desea $F$.

A la vista de este esquema, podemos hacer algunos comentarios:

i) Como vemos, los actos de habla directivo-instructivos son más complejos que los directivos y los descriptivos y combinan muchas de las condiciones de unos y otros. Esto es lo que hace difícil distinguir entre reglas técnicas y proposiciones anankásticas y lo que nos lleva a pensar que las reglas técnicas tienen cierta relación con la verdad. Esta relación existe: tanto en las condiciones preparatorias ( $H$ tiene razones para la verdad de que $A$ es condición necesaria 
de $F$ ), como en la condición de sinceridad ( $H$ cree que $A$ es condición necesaria de $F$ ), como en el contenido proposicional ( $H$ predica una necesidad práctica -basada en un vínculo anankástico- y una acción futura de $O$ ) aparecen elementos relacionados con el mundo del ser y los valores de verdad o falsedad. Esta relación con elementos del mundo del ser se da también en las normas deónticas, aunque en menor medida (en el contenido proposicional). Sin embargo, no creo que por ello pueda decirse que las reglas técnicas son verdaderas o falsas, porque la condición esencial hace que la dirección de ajuste sea mundo a palabras, y no palabras a mundo.

ii) Las condiciones preparatorias de los actos de habla directivo-instructivos son una suma de las condiciones de los actos de habla descriptivos y los directivos (al que se añade el deseo de $O$ de $F$ ). Esto es así porque las reglas técnicas se fundamentan, como ya hemos dicho, en proposiciones anankásticas. Por su parte, que $O$ desee $F$ es necesario, junto con el vínculo que expresa la proposición anankástica, para que surja la necesidad de hacer $A^{45}$. Si la directiva se tratara de una orden o de una norma tendría una condición preparatoria adicional: que $H$ esté en una posición de autoridad frente a $O^{46}$. Esta condición, sin embargo, nunca se da en los actos de habla directivo-instructivos: no hay autoridades -salvo en el sentido de autoridades teóricas- en las reglas técnicas.

iii) Cabe plantearse si en las condiciones preparatorias de los actos de habla directivo-instructivos ha de exigirse que la proposición anankástica presupuesta sea verdadera o si basta con que el hablante tenga razones para pensar que lo es. Si optamos por la primera de las posibilidades, no existirán reglas técnicas basadas en vínculos anankásticos inexistentes. El acto de habla directivo-instructivo no llegaría a tener lugar. Pero me parece más razonable pensar que la regla técnica existe aunque la proposición anankástica sea falsa. Se mantiene así la analogía con las descripciones: una descripción como «Los centauros raptan a las vírgenes llevándoselas al galope sobre sus lomos en las noches primaverales bajo la luna llena» es una descripción falsa, equivocada, pero sigue siendo una descripción; una regla técnica como «Si quieres volverte invisible tienes que invocar a Belcebú, mezclar la sangre de un gato negro y la de un gato pardo y decir abracadabra, pata de cabra» es una regla técnica equivocada -pero regla técnica, al fin y al cabo-

\footnotetext{
${ }^{45}$ Por ello, como hemos visto (nota 5), von Wright sugería que, si bien las reglas técnicas son
} categóricas, su existencia es hipotética y está condicionada al deseo del destinatario.

${ }^{46}$ Searle, Actos de habla, pág. 74. 
y, por tanto, no apta para conseguir el fin deseado. En este sentido es ineficaz, lo que no quiere decir que carezca de función directiva (como ocurre con las supersticiones).

iv) Otra pregunta que nos podemos hacer a propósito del vínculo anankástico es si realmente el medio ha de consistir en una condición necesaria del fin o si puede tratarse de una condición suficiente o meramente contribuyente (esto es, ni necesaria ni suficiente, pero que ayuda a la consecución del fin). Creo que no hay una contestación categórica para esta pregunta: ciertas condiciones suficientes se pueden volver condiciones necesarias dependiendo del contexto; la disyunción de todas las condiciones suficientes de un fin es condición necesaria (y suficiente) de ese fin $^{47}$; una condición contribuyente puede ser todo lo que podemos hacer en un momento determinado; puede ser absurdo realizar un medio que es condición necesaria de un fin si no puede completarse el contexto causal para convertirla en necesaria y suficiente, etc. Todas estas consideraciones deberían tenerse en cuenta para determinar si en un caso nos encontramos o no ante una regla técnica, es decir, si en realidad se está dirigiendo o no la conducta. Quizá podría establecerse una graduación dentro de las reglas técnicas según que las razones para actuar sean más o menos compulsivas. Si el medio es condición necesaria y suficiente del fin, la razón para realizar el medio es mucho más compulsiva que si se trata de una condición suficiente o contribuyente ${ }^{48}$.

v) ¿Ha de ser necesariamente causal la relación anankástica? Creo que podría tratarse de una necesidad lógica o conceptual o también de algún tipo de necesidad convencional. Asociadas a las reglas de los juegos, por ejemplo, surgen «necesidades» técnicas o estratégicas (como tener que mover la reina para hacer jaque mate en una situación determinada $)^{49}$.

vi) Las condiciones preparatorias son condiciones de la existencia misma de las reglas técnicas. Por el contrario, el incumplimiento

${ }^{47}$ Si $p, q$ y $r$ son, por separado, todas las condiciones suficientes de $s$ que pueden darse, realizar la acción molecular $p v q v r$ es condición necesaria de $s$.

${ }^{48}$ Sobre esto puede verse von Wright, Freedom and Determination, Acta Philosophica Fennica, 1980, vol. XXXI, núm. 1, págs. 30 y ss.

${ }^{49}$ En este sentido, Gregorio Robles señala tres tipos de necesidad: causal, «en cuya virtud siempre que acontece un suceso determinado, ocurre otro acontecimiento determinado»; lógica, «en cuya virtud siempre que alguien desee pensar o razonar con corrección formal habrá necesariamente de hacerlo de acuerdo con determinadas reglas»; y convencional, «la cual surge no -diríamos- de la 'naturaleza de las cosas', sino de una convención establecida por tales o cuales razones». Gregorio Robles, Las Reglas del Derecho y las Reglas de los juegos, Universidad de Palma de Mallorca, 1984, pág. 239. 
de alguna condición de sinceridad, como he indicado antes, da lugar a actos de habla «abusivos». El incumplimiento de la condición de sinceridad en los actos de habla directivo-instructivos puede dar lugar con frecuencia a directivos encubiertos (en la educación de los niños tenemos ejemplos de directivos encubiertos en los que falta la condición de sinceridad que los «directivo-instructivos» comparten con los actos de habla descriptivos).

vii) La condición de sinceridad que los directivo-instructivos comparten con los directivos está matizada de alguna manera. La razón por la que $H$ desea que $O$ haga $A$ ha de ser el deseo que $O$ tiene de $F$. El deseo de $H$ es, en este sentido, secundario. No es un deseo «interesado», sino -podríamos decir- «altruista». $H$ desea que $O$ haga $A$ por el bien de $O$. El deseo que $O$ tiene de $F$ se transmite al medio (es una regla de racionalidad práctica desear los medios necesarios para el fin que deseamos, al menos prima facie), así que, en definitiva, $H$ desea que $O$ haga $A$ porque presume que $O$ quiere hacer $A$. ¿Qué sucede si el deseo de $H$ no es altruista? Creo que, de nuevo, nos encontraríamos con algún tipo de directivo encubierto.

viii) Los actos de habla directivo-instructivos comparten con los actos de habla directivos su condición esencial: ambos cuentan como un intento de dirigir la conducta. Esto significa que si $H$ dirige a $O$ una regla técnica, luego no puede negar que pretendía dirigir su conducta por la razón de que $O$ deseaba $F$. La condición esencial de los actos de habla directivo-instructivos es la misma que la de los actos de habla directivos, aunque «cualificada» de diferente manera (la razón por la que $H$ intenta que $O$ haga $A$ es, en los actos de habla directivo-instructivos, el deseo de $O$ de conseguir $F$; por el contrario, en los actos de habla directivos los deseos de $O$ no forman parte necesariamente de los motivos de $H$ para intentar que haga $A$ ). Esto es importante, porque los directivo-instructivos se acercan más a los directivos que a los actos de habla descriptivos. Aunque el resto de condiciones sea una combinación de las condiciones de los actos de habla descriptivos y directivos, la condición esencial «se lleva» a los directivo-instructivos «al terreno» de los directivos o, por lo menos, los acerca. La intención del hablante es en ambos dirigir la conducta; la dirección de ajuste es en ambos mundo a palabras.

ix) Que los actos de habla directivo-instructivos sean un tipo de actos de habla directivos (o estén más cerca de éstos que de los actos de habla descriptivos) no significa que podamos equiparar reglas técnicas y reglas deónticas. Como he indicado anteriormente, mientras que de las normas deónticas surge un deber, las reglas técnicas sugieren una actuación señalando una necesidad práctica. Esto 
puede ser explicado en términos de «razones para la acción», utilizando el aparato conceptual introducido por Joseph Raz en Practical Reason and Norms ${ }^{50}$. En palabras de Juan Carlos Bayón:

«A su juicio [a juicio de Raz] las razones para actuar son 'hechos' [en un sentido muy peculiar que no viene al caso] y los enunciados que son descriptivos de 'hechos' que constituyen razones para la realización de cierta acción por un determinado agente actúan como premisas de inferencias prácticas. El conjunto de 'hechos' tomados en cuenta en una inferencia práctica válida cuyas premisas no sean redundantes constituye un razón completa para la acción a la que se refiere su conclusión. Ahora bien, entre todos esos 'hechos' hay algunos respecto de los cuales creer en su existencia implica tener una actitud crítica práctica (no sería posible, por ejemplo, 'creer en la existencia' de cierto valor sin aprobar eo ipso las acciones que lo promueven o materializan). Los 'hechos' de este tipo constituyen razones operativas. Todos los demás hechos que, junto a las razones operativas, integran razones completas -y respecto de los cuales creer en su existencia es compatible con no tener ninguna actitud crítica práctica determinada-, constituyen razones auxiliares» ${ }^{51}$.

En este esquema conceptual, las reglas deónticas son un tipo especial de razones operativas -razones excluyentes- cuyo papel genuino sería «retirar o desplazar de antemano del razonamiento práctico de un agente un conjunto de posibles razones de signo contrario para todas y cada una de las ocasiones en las que la regla sea aplicable, de manera que la elección del agente para cada una de esas ocasiones quede prefigurada por la regla sin que proceda la reconsideración global caso por caso de la totalidad de razones concurrentes a favor y en contra ${ }^{52}$. Como puede apreciarse, la diferencia entre reglas deónticas y reglas técnicas está en que éstas últimas no pretenden constituir razones excluyentes, sino mostrar -con el fin de dirigir la conducta de un agente- que si es cierto que se tiene

${ }^{50}$ Joseph Raz, Practical Reason and Norms, 2. ${ }^{\mathrm{a}}$ ed., Princeton, NJ, Princeton University Press, 1990. Hay traducción castellana de Juan Ruiz Manero, Razón Práctica y Normas, Centro de Estudios Constitucionales, Madrid, 1991.

${ }^{51}$ Juan Carlos Bayón, «Razones y reglas: sobre el concepto de 'razón concluyente'. de Joseph Raz», Doxa, núm. 10, 1991, pág. 37.

52 Juan Carlos Bayón, «Razones y reglas: sobre el concepto de 'razón excluyente', de Joseph Raz». pág. 39. 
el deseo de un determinado fin (razón operativa), y dado que una cierta acción es condición de ese fin (razón auxiliar), entonces hay una razón completa (pero no excluyente, y que puede ser derrotada por otras razones de más peso) para realizar esa acción. 